\title{
Is There an App for That? A Scoping Review of Apps for Care Workers in the Aged Care Sector
}

\author{
Priyanka VANDERSMAN ${ }^{\mathrm{a}, 1}$ Lua PERIMAL-LEWIS $^{\mathrm{b}}$ and Jennifer TIEMAN ${ }^{\mathrm{a}}$ \\ ${ }^{a}$ College of Nursing and Health Sciences, Flinders University, South Australia \\ ${ }^{\mathrm{b}}$ College of Science and Engineering, Flinders University, South Australia
}

\begin{abstract}
Objective: To identify and review phone applications (apps) that could be used by care workers to help them plan and provide palliative care in the aged and community care setting. Methods: A scoping review. Searches were conducted in App Store and Google Play to identify apps relevant to care workers in the context of palliative and end of life care provision. Relevant apps were downloaded and evaluated. Apps allowing full access were additionally ranked against the Mobile Application Rating Scale (MARS). Information relating to the app as listed in the app stores were also extracted. Results: Of the 1,168 identified apps, only eight could be shortlisted for inclusion. The included apps were mostly English language and developed in high-income countries. The apps were primarily aimed at information provision, with limited content on palliative and end of life care. It was unclear if any of the apps were underpinned by evidence or theoretical frameworks, and none disclosed information on the app development process including involvement of end-users. The mean MARS score for full-access apps was 3.94, with the app iNotice for Carers scoring the highest score of 4.1. Conclusion: Currently available care worker apps appear to have limited functionality and scope in relation to palliative and end of life care. There is opportunity for a co-designed care-worker app development endeavour that is underpinned by robust evidence, and has high-level usability and relevance.
\end{abstract}

Keywords. Care worker, apps, mhealth, palliative care, end of life care.

\section{Introduction}

\subsection{Aging Population}

The global population is aging rapidly. It is estimated that over $16 \%$ of the world's population will be aged over 65 by 2050 [1]. A similar trend is observed in Australia, with over $15 \%$ of Australians aged 65 years or over [2]. While Australians are living longer, their later years are often impacted by chronic life limiting conditions such as cardiovascular diseases, cancer, and neurological conditions [2]. Globally, 23\% of the total global burden of diseases is attributed to older people [3], making them a significant consumer of health, aged and disability care services [2]. While the healthcare sector provides much needed clinical and complex care to older people on an as needed basis, the aged care sector caters for ongoing personal and clinical care needs of many older people.

${ }^{1}$ Corresponding Author: Dr. Priyanka Vandersman, College of Nursing and Health Sciences, Flinders University, GPO Box 2100 Adelaide, South Australia 5001; E-mail: Priyanka.Vandersman@flinders.edu.au 
In Australia, 1.2 million older people receive aged care services either in their homes or in Residential Aged Care Facilities (RACF). To support the continued independence of over $95 \%$ of older Australians living in the community, the Australian Federal Government offers a number of programs [2]. Under these programs, almost a million older people receive personal and clinical care in their homes [4]. With growing numbers of older people with complex co-morbidities continuing to receive aged care services, the aged care workforce is increasingly being expected to cater for the End of Life (EOL) and palliative care needs of their clients. Palliative care is defined as person and familycentred care provided to those with chronic life limiting conditions with little to no prospect of cure, where the aim is to optimise quality of life [5].

More than 366,000 people work across the Australian aged care sector, two thirds of whom are involved in direct care provision [6]. Direct care in the aged care sector is generally provided by the occupational group known as 'care workers' [7]. Care workers spend the largest amount of time directly interacting with residents/clients, while providing personal care activities such as showering, toileting, and helping with meals [8]. These care giving interactions could provide an opportunity for the identification and provision of care that is in line with the palliative approach to care. It should be noted that while planning and provisioning for a comprehensive palliative care plan is not within a care worker's scope of practice, a broader understanding of palliative care could allow them to identify consumer's palliative and EOL care needs; and report these needs to relevant clinical managers (such as senior registered nurses) for further action.

However, with barely $7 \%$ of care workers in Australia receiving any kind of palliative care education [7], much needs to be done in enabling them to support clients and residents with palliative care and EOL needs. Technology and innovation can be viewed as important means of enhancing the capacity of the aged care workforce and smartphone apps are one example of emerging technology solutions.

\subsection{Apps}

Significant advances in smartphone technology and a proliferation of app development has occurred since the release of the first Apple iPhone in 2007 [9]. An app is a selfcontained piece of software, developed for use on mobile devices and made available through app stores [10]. Health related apps make up a significant proportion of available apps. Currently there are over 45,000 healthcare apps available in the Apple App Store alone [11]. Although exercise and wellness apps comprise the majority of such apps, a growing number of apps are available to assist professional care providers at the point of care [12]. There are numerous apps for professional care providers offering assistance with tasks such as drug dose calculations [13], chronic disease management, health risk assessment [14], and access to guidelines [15]. While apps for professional care providers are growing, apps specific to the palliative care workforce also seem to be growing, albeit slowly. A recent systematic review of clinician focused palliative care apps reported 46 apps, many of which were not underpinned by any evidence base [16]. While this review included any palliative care apps targeted at clinicians, the results were not specific to the aged care setting and to care workers. To date, little is known about apps that could be used by care workers in relation to palliative care provision in the aged care setting.

The aim of this study was to identify and review apps that could be used by care workers to help them recognise, report and provide palliative care in the aged and community care settings. 


\section{Methods}

This review adhered to the following five stages: (1) problem identification, (2) literature search, (3) data evaluation, (4) data analysis, and (5) presentation [17]. The reporting of this review adheres to the Preferred Reporting Items for Systematic Reviews and Metaanalyses (PRISMA) statement [18].

The intent was to identify apps that could be used by care workers to help facilitate palliative care practices in the aged and community care settings. Apps were included if they were:

- Intended for use by careworkers

- Intended for use by family carers

- Designed for use by those involved in providing palliative care

- Available for downloading through the major app stores

Apps intended for health professionals working in general aged care were excluded.

Searches were conducted on 18/11/2019 on two leading mobile operating systems which make up $99 \%$ of the global smartphone market [19] (Apple iTunes $\subset$ for Apple and Google Play ${ }^{\mathrm{TM}}$ for Android) using keywords: personal care attendants, careworker, care workers, palliative care support worker, hospice, home palliative care, assistants in nursing, and support worker palliative care. Using the two main app stores enabled us to have a controlled dataset of publicly available apps.

Using the 'copy and paste' function, the following details relating to all of the resulting apps were exported into an MS Excel Spreadsheet: app name, developer's name, price of the app. The next step was de-duplication, and insertion of hyperlinks related to each app in the relevant App stores. Once all the Apps were captured and relevant information was constructed linking the apps to a URL, each app was manually reviewed according to the study protocol. Resulting apps were screened based on their name and description as noted in the App store. The screening and selection of apps was carried out by one author (LPL), and overlooked by another (JT). Any instance of disagreement was planned (apriori) to be resolved via discussion with the third author (PV).

Only those apps that were relevant to care workers or palliative care support workers in the context of aged care were selected for full review and data extraction. Apps meeting the eligibility criteria were downloaded for detailed evaluation and assessment. As this review aimed to explore the full scope of apps available, apps with restricted access (such as institution or region limited apps) were anticipated. Therefore, data extraction of eligible apps that offered limited access was agreed to be carried out based on the app description provided by the developer. Eligible apps that allowed unlimited access were reviewed extensively by exploring every tab/function they offered. Data relating to the features and the content of included apps was extracted and placed in a data extraction table. Apps that allowed full access were evaluated and rated against the Mobile App Rating Scale (MARS) [20]. NVivo 12 Pro was used to analyse the 'information', 'category', 'language', 'availability of App' and 'intended user' fields.

\subsection{The MARS tool}

The MARS is a reliable and objective tool used for assessing the quality of mobile health apps with excellent internal consistency $(\alpha=0.92)$ and interrater reliability $(\mathrm{ICC}=0.85)$ [20]. It includes 23 items across the following three sections: classification, app quality and satisfaction. Each item is rated using a 5-point scale that ranges from $1=$ Inadequate, to $5=$ Excellent. The classification section of MARS covers descriptive information such 
as affiliations, target population and some technical aspects of the app. The quality section includes 19 items and allows evaluation and rating of an app's engagement, functionality, aesthetics, and information quality. The four-item subjective quality section focuses on user satisfaction. The overall MARS score for an app is obtained by calculating the mean scores of the app quality subscales and the total mean score.

\section{Results}

Of the total 1,168 apps identified from both app platforms, only eight met the inclusion criteria (Figure 1). Five apps $(n=5)$ were exclusive to the Android platform, one $(n=1)$ was exclusive to Apple (iOS), and the rest $(n=2)$ were multiplatform.
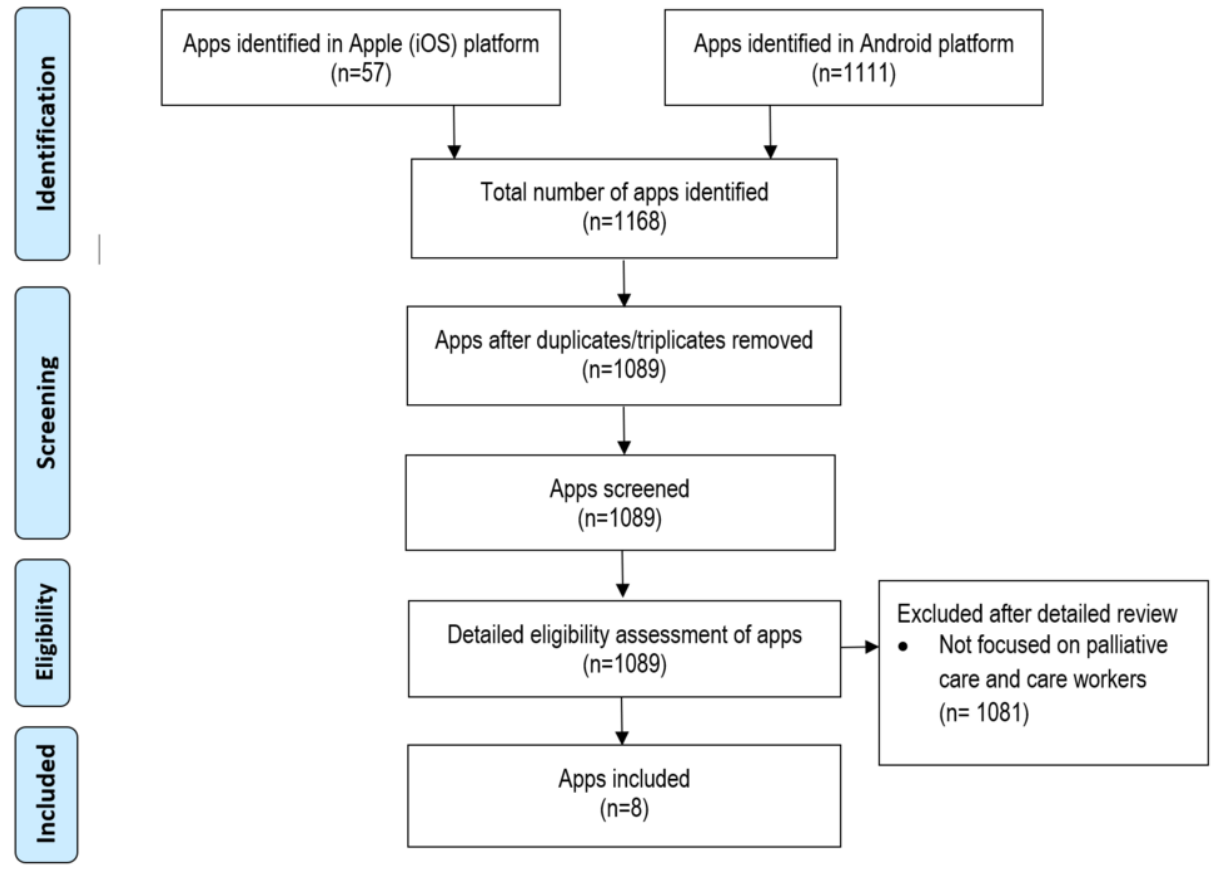

Figure 1. PRISMA flow chart

\subsection{App Characteristics}

The summary of included apps is provided in Table 1 . A majority of the apps $(n=7)$ were developed in high income countries: two in Australia (iNotice for carers, Palliative Care ACT), two in the United Kingdom (UK) (Keys to Care, The Domiciliary Care Worker), one in Ireland (Understand me), one in Germany (Palliative Care), and one in Spain (mPalliative Care App). One app was developed in India, a low-middle-income country (Caregiver). Only one app offered multilanguage (English or Welsh) selection functionality (The Domiciliary Care Worker). A majority of the apps $(n=5)$ were available only in English (iNotice for carers, Palliative Care ACT, Keys to care, Understand me), while one app (Palliative Care) was available only in German. A majority of apps $(n=5)$ allowed unrestricted access (iNotice for carers, The Domiciliary 
Care Worker, Palliative Care ACT, Keys to care, Understand me). Of the three apps that didn't offer unrestricted access, two $(n=2)$ required unique login credentials to use the app (Caregiver, mPalliative care), while the third (Palliative Care) kept crashing and was not functional.

These apps were developed by various groups/authorities such as: government body (iNotice for carers, The Domiciliary Care Worker, Palliative Care ACT), charity organization (Keys to care), health care organization (Caregiver, Palliative Care), and government \& charity partnership (Understand Me). The developer of one app (mPalliative Care) was not identifiable due to restricted access and information provided by the app. In terms of the target audience, half of the apps $(n=4)$ noted that they were targeted at care workers (iNotice, The Domiciliary Care Worker, Understand Me, Keys to care). Two apps $(n=2)$ were targeted at all kinds of palliative care audiences (patients, family, clinicians and care workers) (Palliative Care ACT, Palliative Care), with the remainder focused on professional caregivers in general $(\mathrm{n}=1)$ (Caregivers), and family caregivers $(\mathrm{n}=1)$ (mPalliative care).

\subsection{Content of the Apps}

A majority of apps $(n=6)$ focused on information or guidance (iNotice for Carers, Keys to care, The Domiciliary Care Worker, Palliative Care ACT, Understand me, Palliative Care). The other two focused on the recording of patient assessment data (Caregiver, mPalliative Care). Only one app $(\mathrm{n}=1)$ provided information and guidance specifically based on care workers' scope of practice (iNotice for Carers). Three apps $(n=3)$ included prompts or reminder functions in relation to care provision (iNotice for carers, Keys to care, Caregiver). Two apps $(\mathrm{n}=2)$ provided information relating to official guidelines such as Code of Professional Practice for social care (The Domiciliary Care Worker), and person centred intercultural care (Understand me). While four apps $(n=4)$ included some information on palliative or end of life care (Keys to care, Understand Me, Palliative Care ACT, Palliative Care), information on symptom management and overall care was included in three $(n=3)$ apps (Keys to Care, iNotice for Carers, Palliative care).

\subsection{Critical Appraisal of App Quality}

The five apps that allowed unrestricted access (iNotice for Carers, Keys to care, The Domiciliary Care Worker, Palliative Care ACT, Understand me) were evaluated against the MARS [20]. The app quality mean score of the five apps was 3.94 (IQR 0.1, range 3.90 - 4.10). All apps were designed for adults. Two apps required internet access for use (Keys to Care, PalliativeCareACT), one of which (Keys to Care) allowed social media based information sharing. In relation to the MARS' four domains of App quality, the iNotice for Carers app had the highest mean engagement score at 2.8, with the rest of the apps scoring 2.0 in this domain. All five apps had the same mean scores in the domains of: functionality (4.7); aesthetics (4.0); and subjective quality (2.5). The iNotice for Carers app had an overall quality mean score of 4.1, slightly higher than the overall app quality mean scores of the rest of the apps (3.9) (Understand me, Keys to care, PalliativeCareACT, The Domiciliary Care Worker). 
Table 1. App Characteristics

\begin{tabular}{|c|c|c|c|c|c|c|c|}
\hline App Name & Access & Platform & Developer & Cost & Intended user & Focus & Features \\
\hline $\begin{array}{l}\text { iNotice for } \\
\text { Carers } \\
\text { (Australia) }\end{array}$ & Unrestricted & $\begin{array}{l}\text { iOS \& } \\
\text { Android }\end{array}$ & $\begin{array}{l}\text { NSW } \\
\text { Community } \\
\text { Services and } \\
\text { Health } \\
\text { Industry } \\
\text { Training } \\
\text { Advisory } \\
\text { Body }\end{array}$ & Free & $\begin{array}{l}\text { Care worker } \\
\text { and family } \\
\text { carers }\end{array}$ & $\begin{array}{l}\text { Information } \\
\text { provision }\end{array}$ & $\begin{array}{l}\text { - Designed to assist caregivers in a home environment. } \\
\text { - Provides information on a variety of signs and symptoms that } \\
\text { may be linked to a person's medication management. } \\
\text { - Supports early recognition of indicators and provides relevant } \\
\text { prompts. } \\
\text { - For care workers there is additional guidance about what action } \\
\text { may be taken within their scope of practice. } \\
\text { The 'iPractice' feature includes realistic scenarios covering } \\
\text { common signs and symptoms; and the appropriate responses. }\end{array}$ \\
\hline $\begin{array}{l}\text { Keys to care } \\
\text { (UK) }\end{array}$ & Unrestricted & $\begin{array}{l}\text { iOS \& } \\
\text { Android }\end{array}$ & $\begin{array}{l}\text { Relatives and } \\
\text { Residents } \\
\text { Association }\end{array}$ & Free & $\begin{array}{l}\text { Care worker } \\
\text { and family } \\
\text { carers }\end{array}$ & $\begin{array}{l}\text { Information } \\
\text { provision }\end{array}$ & $\begin{array}{l}\text { - Practical guidance to help improve the health and wellbeing of } \\
\text { those being cared for. } \\
\text { - Guidance on topics from continence care to emergencies. } \\
\text { - Provides reminders of what to think about, ask and do. } \\
\text { - } \quad \text { Offevides news and information, } \\
\end{array}$ \\
\hline $\begin{array}{l}\text { The } \\
\text { Domiciliary } \\
\text { Care Worker } \\
\text { (UK) }\end{array}$ & Unrestricted & iOS & $\begin{array}{l}\text { Social Care } \\
\text { Wales }\end{array}$ & Free & Care workers & $\begin{array}{l}\text { Information } \\
\text { provision } \\
\text { and } \\
\text { guidance }\end{array}$ & $\begin{array}{l}\text { - } \quad \text { Describes what is expected of home care workers. } \\
\text { - Offers tailored, practical guidance to guide and support care } \\
\text { workers in their work. } \\
\text { - Builds on the Code of Professional Practice for Social Care. }\end{array}$ \\
\hline $\begin{array}{l}\text { Understand } \\
\text { Me (Ireland) }\end{array}$ & Unrestricted & Android & $\begin{array}{l}\text { Communicate } \\
\text { your health } \\
\text { Ireland }\end{array}$ & Free & $\begin{array}{l}\text { Health } \\
\text { professionals } \\
\text { and ancillary } \\
\text { staff }\end{array}$ & $\begin{array}{l}\text { Information } \\
\text { provision }\end{array}$ & $\begin{array}{l}\text { - Resource to assist health care professionals in caring for } \\
\text { patients from diverse ethnic, religious and cultural groups. } \\
\text { Practice guidelines for person centred intercultural care and the } \\
\text { provision of interpreter services. } \\
\text { - Information on caring for ill and dying patients from culturally } \\
\text { and linguistically diverse backgrounds, including palliative } \\
\text { care. }\end{array}$ \\
\hline
\end{tabular}




\begin{tabular}{|c|c|c|c|c|c|c|c|}
\hline $\begin{array}{l}\text { Palliative } \\
\text { Care ACT } \\
\text { (Australia) }\end{array}$ & Unrestricted & Android & $\begin{array}{l}\text { Palliative } \\
\text { Care ACT }\end{array}$ & Free & $\begin{array}{l}\text { Anybody with } \\
\text { interest in } \\
\text { palliative care: } \\
\text { patients, } \\
\text { family, carers } \\
\text { and clinicians }\end{array}$ & & $\begin{array}{l}\text { Enables quick and easy access to information on palliative care } \\
\text { when not in front of a computer. } \\
\text { - To influence, foster and promote the delivery of quality care at } \\
\text { end of life for all and to offer compassion and support to those } \\
\text { with a life limiting illness, their carers and families. } \\
\text { - Promote palliative care in the community. } \\
\text { - Provide education on aspects of palliative care. } \\
\text { - Deliver volunteer palliative care services to support clients and } \\
\text { their families with care, compassion, respect and dignity. } \\
\text { - Advocate for best quality palliative care services. }\end{array}$ \\
\hline $\begin{array}{l}\text { Caregiver } \\
\text { (India) }\end{array}$ & Restricted & Android & $\begin{array}{l}\text { Madhavbaug } \\
\text { Clinic }\end{array}$ & Free & $\begin{array}{l}\text { Professional } \\
\text { care givers }\end{array}$ & $\begin{array}{l}\text { Communicat } \\
\text { ion, care } \\
\text { facilitation, } \\
\text { medication } \\
\text { management }\end{array}$ & $\begin{array}{l}\text { - Allows a caretaker/caregiver to provide compassionate care and } \\
\text { personalised eldercare services while the kin or relatives are } \\
\text { notified of each healthcare events of their loved ones. } \\
\text { - Care worker can create resident profile within the app, add } \\
\text { event, alerts, and appointments. } \\
\text { - Health data including vital signs, limits for vital signs and } \\
\text { prescribed medicines, can also be stored within the app. } \\
\text { - App also offers the function to call/chat. }\end{array}$ \\
\hline $\begin{array}{l}\text { mPalliative } \\
\text { Care (Spain) }\end{array}$ & Restricted & Android & Unknown & Free & $\begin{array}{l}\text { Family } \\
\text { caregivers }\end{array}$ & & $\begin{array}{l}\text { - Patient assessment tools included, likely to be administered by } \\
\text { family caregiver. }\end{array}$ \\
\hline $\begin{array}{l}\text { Palliative } \\
\text { care } \\
\text { (Germany) }\end{array}$ & $\begin{array}{l}\text { App crashing } \\
\text { constantly }\end{array}$ & Android & Care Impulse & $\$ 5.99$ & $\begin{array}{l}\text { Anybody with } \\
\text { interest in } \\
\text { palliative care: } \\
\text { patients, } \\
\text { family, carers } \\
\text { and clinicians }\end{array}$ & & $\begin{array}{l}\text { - } \quad \text { German language app. } \\
\text { - } \quad \text { Prformation on current studies, therapies, and symptoms. } \\
\text { hospice care and interdisciplinary cooperation in the German- } \\
\text { speaking countries. } \\
\text { - Useful tips and tricks for helping palliative care patients. }\end{array}$ \\
\hline
\end{tabular}




\section{Discussion}

Despite identifying over 1,000 apps that may have been relevant to care workers, this review identified only eight apps as having sufficient relevance to careworkers around EOL or palliative care to be included. This highlights a potential issue for careworkers, aged care service providers and others seeking to identify potentially relevant palliative care and EOL mobile resources. The analysis of content also suggests that currently available apps are not particularly relevant and useful for the end of life context and may not recognise the specific scope of practice of careworkers who are not trained as health professionals. Careworkers offer a supportive care role rather than direct health care provision such as symptom assessment, care planning or therapeutic interventions. Currently available care worker apps do not seem to adequately support the EOL caregiving role of the very multicultural care worker workforce, and the multicultural Australian community. Nonetheless, some valuable insights have been generated about the content, quality, and scope of these apps.

While groups having some authority in a health or aged care field produced a number of apps, the app information did not make clear whether the app content was evidence based and current. This is a concerning weakness as it does not assist users to be confident in selecting currently available apps. While there is no gold standard approach to the development of health apps [21], there is a general consensus that the content of a health app should be evidence based, adaptable, useful, and not pose any significant risk to the user [22]. The need for evidence-based content is of paramount importance in the context of care worker apps, where the information provided is likely to be relied upon by end users in planning and delivering care to older and vulnerable clients within a very demanding work environment $[7,8]$.

Similarly, it was unclear from the review if any of the apps were developed using a co-design approach, where relevant stakeholders (such as: researchers, developers, sector experts, and end-users) are involved throughout the design, development and user-testing stages [23]. Lack of end-user engagement could lead to the development of products that do not meet the needs of the intended users, resulting in app underutilisation or misuse $[24,25]$. Involvement of end-users can ensure that the resulting app has high level "usability' and 'ease of use'; both of which are crucial precursors for technology adoption and engagement as per the Technology Acceptance Model [26]. Similarly, involvement of academic and sector experts could help ensure that the content of the app is based on robust evidence, and relevant local and national guidelines [27, 28].

All of the apps were designed for written information provision, with none including any interactive or actionable elements. Provision of large volumes of text-based information via apps that are predominantly used in smartphones with small screens is an area of concern, especially as there is evidence to indicate that users find reading on small screens challenging [29, 30]. Even aside from the potential offered by advanced computing and sensor-based functions [31], interactive and video based content could easily be included to improve functionality and, more importantly, engagement by intended users.

Given that most of the information provided in the apps was geared towards improvement of care workers' understanding of best care practices when needed [32], there appears to be over reliance on a passive information dissemination strategy. Inclusion of audio and/or visual material could lead to relatively greater recall of information [33]. Optimising the learning and recall opportunities in care worker apps is 
crucial given care workers workload, where they are often required to perform their daily care activities under significant time pressure [7].

It is interesting to note that only a very small number of apps included information on palliative and EOL care. This is an area of growing importance in aged care as care provision will inevitably include care for older people at the end of their life. Given that careworkers are closely involved with care delivery to older people (many of whom could be approaching the end of their life in the residential and home care setting [34, 35], the presence of limited palliative and EOL care information in the currently available apps represents a missed opportunity. Inclusion of evidence-based palliative care information that is within the scope of a care worker's practice could increase the range and value of careworker apps. This could include information on how to respond when a client raises issues about advance care planning or end of life changes, or information on common symptoms and changes experienced by older Australians. Issues on how to manage grief and loss for clients and for themselves may also be valuable.

A notable limitation of the included apps was their lack of diversity. A majority of the apps were English language apps. Only one app offered multi-language functionality (Welsh), and another included some information on intercultural care. Further, the content of most of the apps was shaped by predominantly Western/Eurocentric perspectives of dying and EOL care. Such lack of multi-language functionality and diversity could act as a barrier to the use of potentially effective apps by the Australian aged care workforce, where $30 \%$ of care workers are born outside Australia [7]. While it is assumed that (at least) basic English language proficiency is necessary for employment in the Australian aged care sector, some members of the workforce may be more likely to engage with an app in their native language, especially if the content of the app covers sensitive topics such as palliative and EOL care [36]. Acknowledgement of the fact that EOL and palliative care are culturally and philosophically loaded constructs [36], and that this care is provided to a very diverse Australian community by an equally diverse aged care workforce is necessary when developing a good quality care worker app.

The MARS based evaluation of the apps revealed that currently available apps do not have a very high-quality score (3.9-4.1). This is not surprising given that the development of mobile health apps remains largely unregulated. Apps providing general information are not classed as a 'medical device', and are therefore not regulated by authorities such as the Therapeutic Goods Administration (Australia)[37], or the Food and Drug administration (United States)[38]. Such lack of control or regulation has led to an overproduction of health apps without safety and privacy assurances; and where the credibility of the developing team and the quality of the app content are largely unknown. [22].

\section{Limitations}

Some limitations should be considered when interpreting the results of this review. Firstly, we conducted our search in Australia. Apps that are exclusive to app stores of other countries might have been missed by our search. Secondly, although searches of the two most popular app platforms were conducted (App Store and Google Play), some apps hosted exclusively in websites may have been missed in this review. A review of published literature could also have identified additional apps. Finally, while care was taken to evaluate and rate the apps objectively, we acknowledge that some level of subjectivity/bias may have influenced our rating of the apps. 


\section{Conclusion}

Despite the availability of some care worker apps, this review found these apps to be limited in their functionality and scope. Currently available care worker apps seem to lack relevance, usability and any underpinning evidence. Furthermore, apps that cater to the palliative and EOL care giving activities carried out by care workers within their scope of practice were also found to be limited. The development and evaluation of highly relevant, evidence-based care worker apps that could facilitate the palliative and EOL care giving activities of care workers is needed. Future work in the area of care worker app development should consider a collaboration between industry, aged care experts and end-users, with the ultimate aim of developing robust apps underpinned by evidence and shaped by relevant guidelines.

\section{Acknowledgements}

This review was undertaken as part of End of Life Directions for Aged Care (ELDAC) Project. The ELDAC project is conducted by a national consortium of eight partners: Queensland University of Technology (QUT), Flinders University of South Australia (FUSA), University of Technology Sydney (UTS), Palliative Care Australia (PCA), Aged \& Community Services Australia (ACSA), Leading Age Services Australia (LASA), Australian Healthcare and Hospitals Association (AHHA), and Catholic Health Australia (CHA).

\section{Funding}

The ELDAC Project is funded by the Australian Government Department of Health. The views expressed in this article do not necessarily reflect the views of the Australian Government.

\section{References}

[1] Pison G. The population of the world. Population \& Sociétés, 2019; 8:1-8.

[2] Australian Institute of Health and Welfare. Older Australia at a Glance. Canberra: AIHW; 2018. AIHW cat. no. AGE 87. Available from: https://www.aihw.gov.au/reports/older-people/older-australia-at-aglance/contents/summary

[3] Prince MJ, Wu F, Guo Y, Gutierrez Robledo LM, O'Donnell M, Sullivan R, et al. The burden of disease in older people and implications for health policy and practice. Lancet. 2015 Feb;7;385(9967):549-62.

[4] Australian Institute of Health and Welfare. People Using Aged Care. Canberra: AIHW: 2019 [Accessed 20 May 2020]. Available from: https://www.gen-agedcaredata.gov.au/Topics/People-using-aged-care

[5] Palliative Care Australia, National palliative care standards (5th Edition), 2018. Canberra. Available from: https://palliativecare.org.au/wp-content/uploads/dlm_uploads/2018/02/PalliativeCare-NationalStandards-2018_web-3.pdf

[6] Australian Institute of Health and Welfare. Aged Care. Canberra: AIHW; 2019 [Cited 20 May 2020]. Available from: https://www.aihw.gov.au/reports/australias-welfare/aged-care

[7] Commonwealth of Australia (Department of Health). The Aged Care Workforce, 2016, 2017. Canberra. Available from: https://agedcare.royalcommission.gov.au/system/files/2020-06/CTH.0001. 1001.2805.pdf

[8] Radford K, Shacklock, K, Bradley G. Personal care workers in Australian aged care: retention and turnover intentions. Journal of Nursing Management. 2015;23(5):557-566.

[9] BinDhim NF, Trevena L. There's an app for that: a guide for healthcare practitioners and researchers on smartphone technology. Online Journal of Public Health Informatics. 2015;7(2):e218.

[10] Ahmed S, Abdullah Z, Palit R, Rokonuzzaman D. A study of mobile application usage in Bangladesh. International Journal of Computer Science and Engineering. 2015;2(4):6-18. 
[11] Statista. Apple app store: number of available medical apps as of Q1 2020. [Cited 20 May 2020]. Available from: https:/www.statista.com/statistics/779910/health-apps-available-ios-worldwide/

[12] Ventola CL. Mobile devices and apps for health care professionals: uses and benefits. Pharmacy and Therapeutics. 2014;39(5):356-364.

[13] Huckvale K, Adomaviciute S, Prieto JT, Khee-Shing Leow M, Car J. Smartphone apps for calculating insulin dose: a systematic assessment. BMC medicine. 2015;13(106).

[14] Lee H, Sullivan SJ, Schneiders AG, Ahmed OH, Balasundaram AP, Williams D, et al. Smartphone and tablet apps for concussion road warriors (team clinicians): a systematic review for practical users. British Journal of Sports Medicine. 2015;49(8):499-505.

[15] Kang H, Park, HAA. A mobile app for hypertension management based on clinical practice guidelines: development and deployment. JMIR mHealth and uHealth. 2016;4(1):e12.

[16] Meghani SH, MacKenzie MA, Morgan B, Kang Y, Wasim A, Sayani S. Clinician-targeted mobile apps in palliative care: a systematic review. Journal of Palliative Medicine. 2017;20(10):1139-1147.

[17] Whittemore R, Knafl K. The integrative review: updated methodology. Journal of Advanced Nursing. 2005;52(5):546-553.

[18] Moher D, Liberati A, Tetzlaff J, Altman DG; PRISMA Group. Preferred reporting items for systematic reviews and meta-analyses: the PRISMA statement. Annals of Internal Medicine. 2009;151(4):264-269.

[19] International Data Corporation. Smartphone OS market share, 2016 Q3. 2016. [Cited 24 January 2017]. Available from: https://www.idc.com/promo/smartphone-market-share/os

[20] Stoyanov SR, Hides L, Kavanagh DJ, Zelenko O, Tjondronegoro D, Mani M. Mobile app rating scale: a new tool for assessing the quality of health mobile apps. JMIR mHealth and uHealth. 2015;3(1):e27.

[21] Van Velthoven MH, Smith J, Wells G, Brindle D. Digital health app development standards: a systematic review protocol. BMJ open. 2018;8(8):e022969.

[22] Llorens-Vernet P, Miró J. Standards for mobile health-related apps: systematic review and development of a guide. JMIR mHealth and uHealth. 2020;8(3):e13057.

[23] Woods L, Roehrer E, Duff J, Walker K, Cummings E. Co-design of a mobile health app for heart failure: perspectives from the team. Studies in Health Technology and Informatics. 2019;266:183-188.

[24] Maguire M. Methods to support human-centred design. International Journal of Human-Computer Studies. 2001;55(4):587-634.

[25] Schnall R, Rojas M, Bakken S, Brown W, Carballo-Dieguez, Carry M, et al. A user-centered model for designing consumer mobile health (mHealth) applications (apps). Journal of Biomedical Informatics. 2016;60:243-251.

[26] Davis FD. Perceived usefulness, perceived ease of use, and user acceptance of information technology. Management Information Systems Quarterly. 1989:13(3):319-340.

[27] Reynoldson C, Stones C, Allsop M, Gardner P, Bennett MI, Closs SJ, et al. Assessing the quality and usability of smartphone apps for pain self-management. Pain Medicine. 2014;15(6):898-909.

[28] Craven MP, Lang AR, Martin JL. Developing mhealth apps with researchers: multi-stakeholder design considerations. In: Marcus A, editor. Design, user experience, and usability. user experience design for everyday life applications and services: Springer; 2014. p. 15-24.

[29] Sanchez CA, Goolsbee, JZ. Character size and reading to remember from small displays. Computers \& Education. 2010;55(3):1056-1062.

[30] Chen CH, Chien YH. Reading Chinese text on a small screen with RSVP. Displays. 2005;26(3):103108.

[31] Islam N, Want R. Smartphones: past, present, and future. IEEE Pervasive Computing. 2014;13(4):8992.

[32] Watson PWB, McKinstry B. A systematic review of interventions to improve recall of medical advice in healthcare consultations. Journal of the Royal Society of Medicine. 2009;102(6):235-243.

[33] Bol N, Van Weert JC, de Haes HC, Loos EF, Smets EM. The effect of modality and narration style on recall of online health information: results from a web-based experiment. Journal of Medical Internet Research. 2015;17(4):e104.

[34] Leclerc, B.-S, Lessard S, Bechennec C, Le Gal E, Benoit S, Bellerose L, et al. Attitudes toward death, dying, end-of-life palliative care, and interdisciplinary practice in long term care workers. Journal of the American Medical Directors Association. 2014;15(3):207-213.

[35] Omori M, Jayasuriya J, Scherer S, Dow B, Vaughan M, Savvas S. The language of dying: Communication about end-of-life in residential aged care. Death Studies. 2020:1-11.

[36] Gysels M, Evans N, Meñaca A, Andrew E, Toscani F, Finetti S, et al., Culture and end of life care: a scoping exercise in seven European countries. PLoS One. 2012;7(4):e34188.

[37] Therapeutic Goods Administration. Regulation of software as a medical device. 2018 [Cited 2 December 2019]. Available from: https://www.tga.gov.au/regulation-software-medical-device

[38] Food and Drug Administration. Mobile medical applications: guidance for industry and food and drug administration staff. 2015 [updated 2019; cited 14 October 2015]. Available from: https://www.fda.gov/media/80958/download 